\title{
How Reflective and Critical Norm-Usage Paves the Way to the Public Power of Judgement
}

\author{
Karolina M. Cern ${ }^{1}$ D
}

Published online: 18 October 2019

(c) The Author(s) 2019

\begin{abstract}
The purpose of this paper is to demonstrate that Neil MacCormick's conception of norm-usage makes it necessary to address the concept of the public power of judgement as the key concept for understanding the democratic legitimization of current law. Therefore, firstly I analyse MacCormick's conception of norm-usage, secondly I demonstrate that it leads to the idea of the institutionalisation of judgementalinterpretative practice, and thirdly, I show that the latter paves the way to the public power of judgement. Finally, I argue that this power needs to be elaborated in terms of competencies which are broader than legal skills and legal reasoning, and, further, that these competencies condition the use of both legal skills and reasoning. Importantly, MacCormick's contribution to understanding the public power of judgement-when further developed-may indicate the profound role of comprehending the proper significance of law in a democratic polity and its relationship to the citizenry.
\end{abstract}

Keywords Neil MacCormick - Norm-usage $\cdot$ Sense of justice $\cdot$ Sentimental basis of morality $\cdot$ Interpretative-judgemental cooperation $\cdot$ Moral-democratic competencies

\section{Introduction}

Neil MacCormick introduced a distinction between three kinds of orders: (1) a normative order (morality), (2) an institutional normative order (law), and (3) an institutional order (politics) [12: 1]. This distinction soon became well-known in the field of philosophy and the theory of law because it implied three crucial and groundbreaking theoretical consequences. Firstly, the conceptualisation of the legal system has become detached from the concept of the state [17: 19] and instead, secondly, is conceptualised in terms of "a set of law-making and law-applying institutions and

Karolina M. Cern

cern@amu.edu.pl

1 Faculty of Philosophy, Adam Mickiewicz University, Szamarzewskiego Street 89C, 60-568 Poznan, Poland 
associated practices and attitudes, which, in a mutually reinforcing way, ensure the systemic quality of that normative order" [19: 8]. Thirdly, those legal institutions are characterised by "institutional pluralism" [7: 222] in the sense of a "pluralism of interpretative institutions" [5: 168]. The latter term applies to institutions which are structurally distinct, however they are all oriented towards "interpreting a shared legal system or norms", and also "an unsettled hierarchy of interpretative authority" is assumed [5: 168]. This constitutes the precise backdrop against which the following analysis will be conducted.

Importantly, the distinction between the three kinds of order (morality, law, politics) allowed MacCormick to formulate the idea of legal pluralism, as well as the idea of post-sovereignty [12: Chapters 7, 8] and thus the first theory of law tailored for the European Union, including the processes of its integration and the multicentric character of the European order [20].

\section{Value Pluralism, Legal Pluralism and Reasonable Disagreement}

In the well-known book entitled H.L.A. Hart [14], ${ }^{1}$ MacCormick states that a normative order takes values into account. ${ }^{2}$ Values are here understood as such "fundamental elements in all human consciousness" [14: 4] that without presuming a "disposition to ascribe values to life" and to "our everyday concepts" [14: 64], these everyday concepts would have remained empty. Therefore, values constitute the most profound "underpinning reasons" [14: 65] for action taking. Norms, considered to operate at the level of a normative order, deal with diverse values and the normative order itself is supposed to solve cleavages and discrepancies concerning what one ought to do in certain circumstances, when different values compete or conflict with one another. This, however, this brings the neutrality of the normative order into question [14: 4]. Firstly, we may presume that there is a plurality of norms dealing with certain values and, therefore, there are potential conflicts among them. Secondly, for the reason that the norms are in need of interpretation in particular contexts which concern questions of conduct, it may transpire that there is, at least from time to time, a "disagreement over the interpretation of a norm" [1: 37]. Only this kind of disagreement actually entails moral considerations, and not exclusively ethical ones, because it calls for consideration of rival interpretations and arguments provided both for and against them.

\footnotetext{
1 In this book MacCormick analysed Herbert L.A. Hart's philosophy of law in a way that involved "pressing Hartian arguments further than Hart pressed them" [14: vii. According to the classification proposed by Andrzej Grabowski, the year 1981, in which the first edition of the book was published, marked the beginning of the "transition period (1981-1995), in which [MacCormick began distancing himself from his master's thought, once more taking into consideration the central issues of his own theory of law" [4: 425-426]. In other words, these analyses significantly contributed to MacCormick's elaboration of the idea of legal pluralism.

2 [14: 64ff]. The point is that MacCormick extracts the idea from Hart's conception, and because it is not so easy to agree with this interpretation as an interpretation of Hart's philosophy, it should be ascribed to the MacCormickian concept of the normative order rather than to Hart.
} 
Disagreement may also arise with regard to the normative institutional order and its norms. As MacCormick states: "Every statement of law, both in judicial justifications and in doctrinal commentaries, rests at least on an implicit, and often on an explicit and articulated, interpretative argument. Such arguments presuppose, and often articulate value systems and value judgement" [13: 186]. The said disagreement, therefore, may contribute to debating (balancing to a certain extent) [13: 186] and developing further interpretative arguments, including rival arguments that always exist [13: 154], to considering "rival interpretations" [13: 54] and rival theories [13: 154] as well as (rival) value-judgements, which also provide reasons as justifications of rulings [13: 114] that seek "to solve contradictions [in the law] as they emerge" [13: 54]. And solving contradictions in the law may be regarded as a factor contributing to the development of law.

Thus, the development of an institutional normative order leads towards the construction of diverse institutions of law pertaining to "different branches of law [that] focus on different values or clusters of values" [13: 113], in the sense that "each branch of law has, when studied in detail, a set of value orientations" [13: 114, see 254], and, according to MacCormick, "it is against those very values that we test and eliminate rival rulings in problematic cases" [13: 114]. It is important to note that, according to Jerzy Zajadło, the phenomenon of law actually comprises five dimensions: law formulation (law-giving), the application of law, interpretations, validity and observance [21: 25]. Thus, the discussed issue does not exclusively pertain to the application of law, but to all five dimensions of the phenomenon of law.

These diverse institutions belonging to certain branches of law do not resolve the totality of such value-problems, neither do they claim the universal unity of responses to these value-problems, because, as MacCormick argues, "law does not, of course, have conclusive moral value" [13: 13]. Therefore, these institutions of law offer responses referring only to branch-values [13: 114]. Although the consistency of law and the universality of the reasons are for MacCormick of irreducible value, it must be clarified that he advocates for "defeasible universality" [13: 94]. And this seems crucial here.

Yet, Lars Christian Blichner rightly addresses democratic concern related to the indicated legal pluralism: there is also "disagreement over who should be in charge and who should interpret the norms" [1: 37], and, I would add, who is in charge of identifying the values by means of which rival rulings or other legally binding decisions are eliminated. That is, who should participate in the process of solving these contradictions in law or, to grasp this issue more broadly, who should participate in the development of law. Further: why those and not others-what is the justification for selecting them?

In other words, in order to conceptualise the said disagreement over norms as a democratic - that is, reasonable-disagreement, we need to firstly accept it, secondly, subject the disagreement to the process of reason-giving and reason-taking, as related to arguments made while debating, balancing, considering and further honing rival arguments, evaluative judgements, interpretations and theories. Thirdly, we also need to respond to the problem of the nonauthoritative - and in democracy this means inclusive-indication of participants in the process of exchanging reasons, which means that the expert-dependent settlements must be as reduced and precisely 
justified as is permissible. Fourthly, we need to ensure that the process is accompanied with regard to the democratic credentials best tailored for the acceptance of the self-reflexive transformations of institutional-normative orders, as results of the process. And that the latter, fifthly, takes the plurality of citizens' comprehensive standpoints seriously, meaning that it treats the plurality of reasons seriously. Eventually, we shall be aware that meeting the democratic credentials does not guarantee that the outcomes of the process will not produce new/further contradictions of law and disagreements over them which need to be accepted in order to go through a subsequent process of the same sort.

Disagreement, understood as reasonable disagreement, constitutes a challenge in the field of contemporary public morality, in both theoretical and pragmatic terms. This is the case because the language and discourse of elites has recently been profoundly questioned by those who feel politically marginalised. The point is that the mainstream language (of elites) is purblind to new kinds of social and/or political and/or economic inequalities and injustices which require constructing new sorts of semantics to articulate negative experience, cf. [3, 6]. Thus, the inclusion of this new semantics entails the transformation of mainstream language. Further, the latter is actually conditioned by the transformation of the forms of established public discourse. Unless the readiness and appropriate competencies for these transformations are soundly developed (on the part of certain office holders, including, naturally, different sorts of judges), there will be a lack of clarity regarding how to politically and socially deal with the emotions and moods awakened during debates on that which concerns the public; that is, with the emotions and moods which may lead to social divisions. Naturally, MacCormick does not discuss any new semantics, especially in this context. Most importantly, at first sight, it does not seem clear enough, what might be regarded as the most profound guarantee of the democratic quality of the whole process of making legally binding decisions which also respond to contradictions in law. Nevertheless, my claim is that MacCormick's late philosophy of law indicates a way to solve these problems. In the next two subsections I shall demonstrate firstly how his considerations pave the way to the solution, and, secondly, I shall address the problems which are generated by such a solution, and which require an urgent response.

\section{The Private Power of Judgement and Moral Competence}

In fact, MacCormick strongly insists that "as autonomous moral agents (...) we more resemble (...) judges" than legislators [15: 20]. As Lars Christian Blichner argues, an institutional normative order is "an institutionalised continuation of a normative order (or normative orders)" [1: 32]. Thus, I shall argue below that solving a problem which involves conflicts between the values underpinning the normative order, and further, underpinning an institutional normative order, may proceed basically via institutionalisation of the specific judgemental-interpretative practice within a given context. This institutionalisation is at the heart of the searched for guarantee of the democratic quality of legally binding decisions. 
MacCormick claims that "the moral is that we humans are norm-users before we are norm-creators. If so, it follows that our sense of duty and obligation to each other is and has to be prior to any authoritative imposition upon us" [16: 29]. There are two levels on which the sense of this statement can be understood. The first level indicates the rationality of human action as a precondition of the action itself. Thanks to this rationality, our actions can be foreseen by others. It may be said that when following customs or shared rules we actually cooperate with others, because we let them foresee and reconcile themselves to the way we conduct our everyday affairs. ${ }^{3}$ Therefore, we must primarily be rational, in the sense of being rule-followers, in order to-in the next move-ask about the reasonableness of the rule-driven action, or the rule itself. In the words of MacCormick: "In the development of moral agency, heteronomy precedes autonomy" [10: 1057].

My argument is that we need to pay heed to the crucial link between the stage of the mere rationality of action (rule-following) and the stage of the normativity of action-taking (norm-usage). This crucial link is conceived as a shift involving judging, triggering the power of judgement. MacCormick explicitly states as follows:

Necessarily, normative order involves judgement. Being subject to a norm is being liable to judgement by oneself and by others in case one's conduct does not match up to what is required. (...) To engage with a norm as an acting subject is to judge what must be done in a given context; to reflect in normative terms upon one's own or another's conduct in a given setting is to judge, against some envisaged norm, whether what was done ought to have been done or ought not to have been done. [10: 1057]

The shift involving judging raises the concept of mere rationality, which is here embedded in rule-following, to the level of morality depicted as norm-usage. What is actually shifted is the structure of judgement-formulation: from heteronomous towards autonomous judgement formulation. MacCormick also states that in order to judge something in a moral sense, we need to find ourselves in a given context in which we "draw attention to [demands] of other-regarding" reasons [16: 16]; such a context would be deemed as a locus of moral judgement itself. Thus, this context requires reflective engagement with a norm, that is, engagement which entails delivering — or at least being able to deliver-reasons in favour of and/or against the norm in question.

It is evident that, the key issue here concerns making reflective judgements, so let us take a closer look at this issue. These judgements take into account others involved in the action, because this indeed means norm-usage, performed by an autonomous agent. According to MacCormick, the concept of norm-usage entails that we confront, or at least we need to be ready to confront, our interpretations of the norm (this interpretative practice does not have any canonical formulation [11: 309]) and values underpinning norms with other-regarding reasons. How do we do

\footnotetext{
${ }^{3}$ In order to explain normative orders, MacCormick most often gives the example of the spontaneous forming of a 'queue' (or a 'line'), which often happens in everyday life [15: 13-14, [16: 51-52, [11: 306-307].
} 
that? Taking for granted, on one's own, what values and preferences we and others involved in a given context hold-as arguments in use formulated on the basis of one's reflection over rule-following by others-we "judge what must be done in a given context", we judge (or are ready to judge) what can be regarded as our shared normative opinion and how one ought to perform.

As Lind and Nowak [8] put it with regard to the private (meaning the moral power of judgement), the quality of external, manifest or instituted judgmental behaviour can be called 'competence' - especially moral judgment competence-if, and only if the cognitive moral competence of the corresponding judgment maker is presumed. A person is a competent judgment maker when they are able to deal with issues and decisions of varying difficulty, and to choose a principle-based, decisive argument. Their competence does not relate to their single judgment or decision, but to their entire judgmental practice. Furthermore, this practice should not be reduced to "external operationalization as rule-conforming behaviors (...) if we describe and evaluate behavior in regard to external standards we should not call it the same as internally determined behavior" [8: 140-142].

There are, however, some additional and crucial moments in MacCormick's line of argumentation. First of all, the crux of the claim that human beings are first and foremost norm-users [16: 193-194] is the presumption that reasonableness is constitutional for human beings, and that it primarily takes the shape of cooperation. The latter means here, in short, exhibiting behaviour with regard to shared norms or standards of behaviour [16: 19]. Secondly, behind this primary cooperation with regard to the shared norms or standards, one may find, as a reason justifying the presumption on the reasonableness-the sense of justice of all affected [16: 134, 139]. In order words, according to MacCormick, the idea of the sense of justice justifies, above all, the presumption that human beings are those who have already cooperated and now ask-being capable of judging autonomously-about the impartial terms of cooperation, which essentially contributes to the understanding of reasonableness.

Thirdly, MacCormick also states that "the critical-rational discussion depends on an understanding of real people as they have really acted in the past and go on acting now. (...) Without empathy there is no understanding of (other) people as people. Without understanding of other people, there is no self-understanding" [16: 9]. Why does empathy matter? What is its role in the structure of autonomous interpretative-judgement formulation? Does it supplement in any important way the above presented considerations? My response is that definitely yes, it is a complementary element of the conception under investigation. The point is that without empathy we are blind to (new) specific arguments regarding e.g. forms of injustice and disrespect which are in need of formulating an "intersubjective framework of interpretation"; that is, a new semantics, a new language and perhaps also a new form of public discourse, which — as intersubjective-would be suitable for expressing the (new) form/-s of injustice as typical for a given group of people, cf. [6: 163]. If one relied solely on taking for granted, on one's own, what values and preferences we and others involved in a given context hold-as arguments in use for formulating a judgement on what one ought to do-then one would not be able to formulate the other-regarding reasons relevant in a given context, which is a locus of interpretative 
judgement formulation. In other words, this means that we cannot embark on the inclusion of the other (in the engagement with the norm) with the imposition of concepts and terms on them, their situation or their reasons/beliefs/convictions and so on. This is how we should understand that "Human conduct engages both reason and emotion. Acting well and wisely means acting for good reasons, and these must fully allow for affective as well as our intellectual nature" [16: 1]. The very locus of interpretative judgement formulation lets the affects and reasons meet and fit one another, so it cannot be understood as an exclusively abstract dimension of reasoning.

Thus, in my opinion, MacCormick understands morality rather as being based on the requirement of impartiality, due to the presumption of the sense of justice which, together with the power of judgement, triggers bottom-up moral considerations (that is, considerations always stemming from a particular context that gives rise to a moral dilemma) and, eventually, the norm-giving momentum as a basis for autonomous self-conduct. Drawing on the Scottish Enlightenment, rooted in empirical investigations regarding morality, or at least investigations rooted in moral sentiments, that are always context-dependent, he argues for "defeasible universality" [13: 94]. As MacCormick asserts, "the practical character of morality is sufficiently guaranteed by its having this sentimental basis" [16: 57], and universalizability, understood as a certain procedure or test, is unable to reach this moral basis [13:21]. All of this is important and instructive for understanding what is actually institutionalised — or rather what should be institutionalised, if the democratic quality of law is to be enhanced and protected-within the institutional normative order.

My thesis is that MacCormick's considerations on the relationship between morality and law lean on the public power of judgement, whose locus is intersubjective. This entails that the full-blown understanding of reasonableness comprises processes involved in the public justifications of common action norms. Instead of taking for granted, on one's own, what values, preferences, interpretations and so on are held by others involved in a given institutional normative context (and what is typical for moral/private power of judgement), one needs to really engage with the norm together with the others affected by it-carefully listen to them, try to understand what they intend to say, try to make one's own position and justification clear to them using an understandable language, convince them by evoking what is understandable to them, then eventually and cooperatively find a new solution; a new formulation of the norm in question. In other words, while the private (moral) power of judgement presumes delivering — or being ready to deliver-a specific line of argumentation in favour of and/or against the given norm in question, so the public power of judgement presumes real normative cooperation in the elaboration of publicly shared reasons which justify common action norms pertaining to a given branch of law. This cooperation over justifications is crucial, because, as MacCormick states, since the moral practice of judging with regard to the values underpinning norms constitutes a normative source of the institutional normative order, "it is more plausible to think that the good moral agent is the model that well-designed judicial systems seek to institutionalise" [16: 66]. Of course, in no case is the mere judging "all-important" [16: 198]. In other words, what becomes institutionalised in the institutional normative order is basically the argumentative-judgemental feature 
of moral reasoning, because law is "intrinsically arguable" [15: 260]; moreover, both law and morality are supported by the practical-judgemental reasoning of the same genus [16: 4].

MacCormick seems to argue that principles cannot be imposed from the topdown perspective of an institutional normative order that rather forms "chains of institutions" focused around the branches of law and generating, to a certain extent, contradictions [13: 53-54]. Thus, it is impossible to build "a complete and wholly satisfactory theory of the interpretation of an entire legal system" [13: 54]. In such a situation the need for real problem-solving in law rather calls for departing from, as MacCormick indicates, "commonplaces" and reaching new, perhaps broader and deeper commonplaces - articulated, then, in terms of principles. Thus, what needs to be actually institutionalised as a continuation of normative orders is a specific reasoning which pays heed to the plurality of values, the interpretations of norms, and the evaluative judgements and theories provided as arguments justifying the common action norm in question. Most importantly, however, considering in a given context the specific situation of the other affected by the norm in question requires institutionalisation-despite the fact that institutionalisation of empathy seems impossible. Therefore, empathy needs to be conceptualised in some other way in processes which are impartial and made in the intersubjective locus (taking people as they have actually been and still are in their everyday conduct) of decisionmaking and action-taking, rather than with the consideration of 'pure' reasons for action, or in seeking a consensus over the theory of the body of law. A response to this issue, such as increasing the involvement of stakeholders in legally binding decision-making processes, in order that they can speak for themselves and articulate their claims, would also constitute part of a constructive response to Blichner's earlier question of who is entitled to resolve disputes arising at the level of the institutional normative order (and why they are thus entitled). Such a response would necessarily take the context of the decision making process into consideration.

It is precisely this sense of justice, the cooperation and impartiality of judgements that seem to defend the law-in MacCormick's view-against its unification, which entails moralisation and destroys the power of judgement.

Drawing on the tradition of the Scottish Enlightenment's moral philosophy, he seems to argue that ethical persons ${ }^{4}$ - that is, those who realise a certain set of values - are those who are actually interested in cooperating on fair terms with other ethical persons, and within the judgemental-argumentative settings designed for constructing the common action norms that may bear fruit in a kind of reasonable disagreement [13: 117, 163, 261]. He calls this "a fair balance" expressed in law, because it is more likely to be achievable than consensus. Crucially, this "fair balance", understood as "the reasonableness of the provision and of the possible objections to it" [13: 184], stems from the reasonable disagreement of the persons involved in "attending fairly" [13: 163] to the issue in question, and who invoke

\footnotetext{
${ }^{4}$ Marcin Jan Byczyński demonstrates why we can talk about a person only if the intersubjective dimension of their existence, i.e. the dimension of social relations mediated in social institutions, e.g. in law, is secured, cf. [2].
} 
the plurality of reasonable grounds for formulating their judgements, including the affects and diverse/competing interpretations of values and preferences, and their meaning, on their lives.

As one may see, MacCormick does not seem to be afraid of transitions in the law and their implications for the political community. The endorsement of reasonable disagreement in the case of law entails, for example, the inevitable dynamic of the plurality of law under international law.

\section{The Public Power of Judgement and Moral Discursive Competencies}

Thus far I have analysed the question of issuing a moral judgement in MacCormick's conception. For MacCormick, it is characteristic that: (1) norm-usage presupposes a sense of justice; it is aimed at agreeing on fair terms of cooperation, and in this sense is reflectively constructed upon earlier and heteronomic rule-following, which ensures the rationality (and therefore also predictability) of our actions, and in this aspect presupposes our actual cooperation with others; (2) moral judgment is autonomous, (3) however, this autonomy is cognitive-affective in nature, since moral judgment takes into account both the reasons-referring above all to values and preferences of those who are affected-as well as the affections and empathy of the autonomous agent's towards others, which is exactly what makes normative judgment take into account other-related reasons. Thus, (4) normative judgment has the form of interpretative-judgemental practice, which also aims to extract that which is specific to a particular person or group in a given problem context, but deserves to be extracted within an "intersubjective framework of interpretation" as meaningful to others as well. (5) Reasonableness is bound up with reasonable disagreement. It does not entail ignoring affects, but rather incorporating them into discourse by transforming them into arguments relevant to the widest possible audience, which, however, is not always possible, due to differences in everyday experience, wherein, to a certain extent, the terms in which normative claims are formulated are rooted. (6) Normative judgment presupposes that a moral agent, on their own, considers the above as arguments to be used for formulating judgements on what one ought to do. What needs to be clarified is the answer to the question of what exactly the institutionalization of interpretative-judgemental practice is; or, that is, what the public power of judgement is precisely. Therefore, I will concentrate on indicating what follows from the above considerations and deserves precise consideration, being crucial for understanding the relationship between the law and contemporary democratic governments. In other words, I will indicate the problems that require urgent research.

Consequently, on a fundamental level, I agree with Menéndez, who argues that:

by highlighting the connection between the normative and the institutional imagination of human beings and law, the institutional theory of law not only makes us see European constitutional conflicts as normal, but also stresses that integration cannot rest on law de facto providing one single authoritative 
answer to all legal problems. The stability of Community law does not depend so much on the provision of one right answer through one single master rule, as on the affinity of the legal system and on political deliberation and bargaining, reasoning and decision-making. [18: 226]

However, a number of problems need to be addressed and conceptually elaborated in order to make better use of what I presented as MacCormick's chief achievements.

Firstly, somewhat travestying Menéndez's previously quoted statement, I would rather say that MacCormick's considerations lead him to recognise that 'law must indeed, be understood and theorised not only from the standpoint of institutional actors, but always also from that of addressees of law, that is, citizens'. And this is the crux of the public power of judgement: public justificatory discourse is a form of cooperation within which persons hailing from different lifeworlds (to which each of them needs to take a reflective distance, in order to transform specific experience into intersubjectively accessible normative semantics, which is very hard and actually rarely achieved), as citizens gathered in a given institutional context, collaboratively construct justifications for common action norms. This should transform their private attitude (as moral persons) toward reflective cooperation in a public judgemental attitude (as citizens) and, further, bind citizens' judgements (as publicly significant) with office holders' decisions, so that the latter will take into reflective account the justifications collaboratively put forward by the addressees of law. ${ }^{5}$ As I previously stressed, the exercise of the public power of judgement affects both sides: the addressees of law as citizens, and also office holders. Challenging interpretations develop the chains of law, and if they meet the strong requirements of the democratic justifications of the decisions made within them, then they may also be depicted as a medium of normative inclusion.

Secondly, the concept of the public power of judgement needs to be carefully elaborated in conceptual terms. That means, in my opinion, that public power should be carefully analysed in terms of specific competencies. Yet, in the case of the public power of judgement, and its appropriate competencies, it does not come just about by "choosing a principle-based decisive argument" [8], which is characteristic for the private (moral) power of judgement. Here it rather comes about through real cooperation oriented at constructing justifications that transform rival evaluative judgements, interpretations, values and specific experience into shared reasons, with regard to which it would be possible to establish common action norms, appropriate for a given institutional context. The point is that in such real situations the challenge arises at least due to the following:

- when employing certain terms or concepts, people do not assign the same meaning to them as others do, or at least not always;

\footnotetext{
5 Consider the five dimensions of the phenomenon of law and think of, e.g., public hearings, court trials and lay judges, public consultations, administrative decisions and so on.
} 
- the meanings assigned to terms or concepts by different participants of public discourse are not always empirically rooted in the same experiences, or social, political and economic traditions, etc., because the participants often hail from different lifeworlds, or institutional contexts;

- participants of public discourse often do not employ concepts or terms consistently, because such usage is not the most important value for them: the issue at stake is not the consistency and coherence of the discourse; but rather that participants can use this discourse to give public expression to what concerns them most, to be able to put this into words and render it somehow comprehensible to others; to make their claims noticeable to other interlocutors;

- the use of terms or concepts is often contradictory or inconsistent, precisely because the interlocutors are trying to indicate something new, which has been thus far overlooked, has passed unnoticed in public discussions; something that has yet to be referred to, something that may not have been grasped in the way they think it should be, or that may seem obvious to many, but for some participants in the public discourse it is neither obvious nor trivial;

- the point is rather that public discourse should provide real opportunities for developing new reasons for legally binding decisions, i.e. for re-conceptualized, transformed common action norms.

From this it follows that the specific competencies analysed with regard to the public power of judgement-which, as the guarantee of the democratic quality of legally binding decisions is, as I argue here, to a certain extent distinct from the private power of judgement - can be identified as including the following:

- a competence to judge others (from other lifeworlds) impartially, which is, according to MacCormick, the kind of affective-cognitive competence presuming both: (a) understanding of the other in their specific situation (empathy) related to a given institutional context, that is, understanding what really matters to the other and constitutes a motive for them to participate in the discourse, and (b) the actual exchange of reasons (reflectively giving and receiving them) with the person over the motives relevant for them in a given institutional context in order to justify common action norms within a certain branch of law;

- thus, a competence to listen, understand and contribute to making other normative narratives intersubjectively accessible to a wider audience; here, the affective aspect (empathy) is indispensable for understanding a different normative narrative than our own semantics (because it is rooted in other lifeworlds and other experiences, from which emerge justifications contributing to the construction of common action norms), cf. [3: 155];

- a competence to live in reasonable disagreement, which presumes that it is impossible to reach a consensus over each of our concerns; also this competence is two-fold, and has both affective and cognitive components: respecting the other whom one cannot fully understand, and remaining open to the transformation of both justifications of and common action norms themselves. 
However, that is not enough, alas. If the justified judgements made by addressees of law are to influence institutional decision-makers, then the competencies of citizens vis-à-vis office holders — and vice versa-need to be rethought. I have in mind here the competencies of all those involved in a specific institutional context, decoupled (as far as possible) from their lifeworlds, and making justifications related to principles justifying what is common in action norms while actually being aware of their relevance also to those different lifeworlds.

A given context or institutional setting makes the judgement intersubjectively situated-it is neither too abstract, nor overly particular, which entails a specific movement of reflection: between universal principles [8] and the particular situation of other participants in discourse, in order to construct public justifications best tailored for the type of situation we deal with within the framework of a given institutional context. Further, the competencies in questions pertain to both citizens acting in the public sphere (in institutions belonging to particular branches of law) as well as to citizens acting on behalf of public offices, because the institutionalization of judgement is conditioned by the possibility of discursive cooperation between citizens and officials performing their duties. This is the case because law is not institutionally context-free or institutionally context-independent and, further, its democratic quality depends on its addressees' as well as on office holders' competencies to judge publicly concerning common action norms. The essence of the institutional perspective on law are all those individuals' competencies to judge publicly on issues of common concern. What is important here is that the concept of competence is broader than the concept of legal skills required for correct law-formulation (law-giving), the appropriate application, interpretation and observance of law, and the sound determination of its validity. In other words-and this is the essence of the argumentation presented in this article-the concept of competencies related to the public power of judgement is broader than legal reasoning and, what is more, to some extent it determines legal reasoning. It also goes beyond the design of democratic procedures itself. It is necessary to have well-formed competencies of public judgement formulation in order to properly democratically shape such procedures and apply them. And given the above five dimensions of the phenomenon of law, the concept of competence should be considered for these particular legal phenomena and their participants (both legally trained and lay people).

\section{Conclusions}

It may be said that MacCormick, as a post-positivist thinker, claims that it is not so much social practice (considered as a fact) as the moral (reflective) practice of judging that constitutes the backdrop of law, and it is judgemental-interpretative communication that generates the great force of social integration. Rather than the outcomes of interpretative-judgemental activity, it is this reflexive activity that itself generates the basal power for social integration and the inclusion of others.

The rehabilitation of the critical reflective attitude constitutive of morality, as Augustín José Menéndez argues, exceeds the Hartian project because it leads MacCormick to claim that "law must, indeed, be understood and theorised not from the 
standpoint of institutional actors, but from that of addressees of law, i.e., citizens" [1: 216]. If this is the case, then the dynamic of the development of law entails deeper and broader claims for citizens' discursive participation in diverse institutional settings in order to democratically support, maintain or transform the value pluralism that stands behind those institutional settings and solve contradictions in law, when they appear. Thus, we need appropriately tailored institutions to exercise the public power of judgement (cooperative interpretative-judgemental activity) to democratically justify common action norms, especially those belonging to the public law that makes up the democratic government.

There is a lack in MacCormickian thought of direct connections between law and democratic politics that go beyond the state. This lack of considerations concerning law and democracy seems to be the positivistic burden in his reflection on law. In consequence, the MacCormickian power of judgement is not yet a public power of judgement. This harbours a rather pertinent problem: as the power of judgement is not a public power of judgement, it cannot be seen as a direct source of the legitimisation of the law or politics. In other words, its non-public or rather private character generates a gap between the private judgements which people make in everyday situations and office holders' official judgements, which are democratically legitimised. Consequently, "there is still a conceptual difference between law and democracy" [1: 50] in MacCormick. I would say that MacCormick decoupled law from the concept of the sovereign state [9: 1-18], but did not manage to conceptually couple law with democracy, although he paved the way for directly raising this significant question. As Blichner rightly emphasises, "from the norm-users perspective, law that cannot be reasonably defended in public is not law" [1: 34]; but how one should understand the public power of judgement and the construction of public justifications of legal decisions, that is, operating in the public (intersubjective) locus, calls for urgent elaboration. And that is one of the most profound challenges in the contemporary philosophy of law: to rethink the relationship between law and democracy in terms articulating the possible reasonableness of rule-driven actions as justified in public, so their addressees of law might understand themselves always as the co-authors of these laws.

Acknowledgements The following text was prepared as a part of a research grant financed by National Science Centre (Poland), No. DEC-2015/19/B/HS5/03114. I would like to thank Dr. Marcin Jan Byczyński and Dr. Krystian Szadkowski from the Faculty of Philosophy, and Ph.D. Candidate Stephen Dersley from the Faculty of Anthropology and Cultural Studies, Adam Mickiewicz University in Poznań, Poland, for their constructive remarks and comments, which helped me to prepare the final version of this article.

Open Access This article is distributed under the terms of the Creative Commons Attribution 4.0 International License (http://creativecommons.org/licenses/by/4.0/), which permits unrestricted use, distribution, and reproduction in any medium, provided you give appropriate credit to the original author(s) and the source, provide a link to the Creative Commons license, and indicate if changes were made.

\section{References}

1. Blichner, Lars Christian. 2011. Juridification from Below: The Dynamics of MacCormick's Institutional Theory of Law. In Law and Democracy in Neil MacCormick's Legal and Political Philosophy, 
the Post-sovereign Constellation. Law and Philosophy Library, vol. 93, ed. José Menéndez and John Erik Fossum. Dordrecht: Springer.

2. Byczyński, Marcin. 2014. Intersubiektywne uznanie, czyli personalizacja podmiotu. Filozofia Publiczna i Edukacja Demokratyczna 3(2): 161-178.

3. Cern, Karolina M. 2017. Questioning Equality for Self-reflexive Societies. Dialogue and Universalism 1: 149-163.

4. Gizbert-Studnicki, Tomasz, Adam Dyrda, and Andrzej Grabowski. 2016. Metodologiczne dychotomie. Krytyka pozytywistycznych teorii prawa. Warszawa: Wolters Kluwer.

5. Halberstram, Daniel. 2012. Local, Global and Plural Constitutionalism: Europe Meets the World. In The Worlds of European Constitutionalism, ed. Gráine de Búrca and Joseph H.H. Weiler. Cambridge, NY: Cambridge University Press.

6. Honneth, Axel. 1996. The Struggle for Recognition. The Moral Grammar of Social Conflicts (trans: Joel Anderson). Cambridge, MA: Polity Press.

7. Kirsch, Nico. 2012. The Case for Pluralism in Postnational Law. In The Worlds of European Constitutionalism, ed. Gráine de Búrca and J.H.H. Weiler. Cambridge, NY: Cambridge University Press.

8. Lind, Georg, and Ewa Nowak. 2015. Kohlberg's Unnoticed Dilemma-The External Assessment of Internal Moral Competence? In Kohlberg Revisited, ed. Detlef Garz, Boris Zizek, and Ewa Nowak. Rotterdam: Sense Publishers.

9. MacCormick, Neil. 1993. Beyond the Sovereign State. Modern Law Review 56(1): 1-18.

10. MacCormick, Neil. 1997. Institutional Normative Order: A Conception of Law. Cornell Law Review 82(5): 1051-1070.

11. MacCormick, Neil. 1998. Norms, Institutions, and Institutional Facts. Law and Philosophy 17: 301-345.

12. MacCormick, Neil. 2001. Questioning Sovereignty. Law, State, and Nation in the European Commonwealth. Oxford: Oxford University Press.

13. MacCormick, Neil. 2005. Rhetoric and the Rule of Law. A Theory of Legal Reasoning. Oxford, NY: Oxford University Press.

14. MacCormick, Neil. 2008. H.L.A. Hart. 2nd ed. Stanford, CA: Stanford University Press.

15. MacCormick, Neil. 2008. Institutions of Law. An Essay in Legal Theory. Oxford, NY: Oxford University Press.

16. MacCormick, Neil. 2008. Practical Reason in Law and Morality. Oxford, NY: Oxford University Press.

17. MacCormick, Neil. 2011. MacCormick on MacCormick. In Law and Democracy in Neil MacCormick's Legal and Political Philosophy. The Post-sovereign Constellation. Law and Philosophy Library, vol. 93, ed. Augustín José Menéndez and John Erik Fossum. Dordrecht: Springer.

18. Menéndez, Augustín José. 2011. From Constitutional Pluralism to a Pluralistic Constitution? Constitutional Synthesis as a MacCormickian Constitutional Theory of European Integration. In Law and Democracy in Neil MacCormick's Legal and Political Philosophy, the Post-sovereign Constellation, vol. 93, ed. José Menéndez and John Erik Fossum., Law and Philosophy Library Dordrecht: Springer.

19. Walker, Neil. 2011. The Cosmopolitan Local. In Law and Democracy in Neil MacCormick's Legal and Political Philosophy, the Post-sovereign Constellation. Law and Philosophy Library, vol. 93, ed. José Menéndez and John Erik Fossum. Dordrecht: Springer.

20. Wojciechowski, Bartosz, Marek Zirk-Sadowski, and Mariusz J. Golecki (eds.). 2009. Between Complexity of Law and Lack of Order. Beijing: Wydawnictwo Adam Marszałek.

21. Zajadło, Jerzy. 2008. Po co prawnikom filozofia prawa?. Warszawa: Wolters Kluwer.

Publisher's Note Springer Nature remains neutral with regard to jurisdictional claims in published maps and institutional affiliations. 